\title{
Bezalel Peleg: a bibliography
}

\author{
Hans Peters • Peter Sudhölter
}

Published online: 20 November 2012

(C) Springer-Verlag Berlin Heidelberg 2012

\section{Prologue}

Bezalel Peleg (1936) completed his PhD in mathematics under the supervision of Robert J. Aumann at the Hebrew University of Jerusalem in 1964. He worked at the Institute of Mathematics of the same university since 1962 until his retirement, and was appointed full professor in 1976. At the moment he is a member of the Center for the Study of Rationality at the Hebrew University. Since 1965 he was a visiting professor at many different institutes in the US and Europe. He was a member of the editorial boards of Econometrica, Journal of Mathematical Economics, International Journal of Game Theory, Social Choice and Welfare, Games and Economic Behavior, and Economic Theory. Since 1977 he is a Fellow of the Econometric Society. He has published around $128^{1}$ articles in game theory, social choice theory, and economic theory in general, and he has published three books. His complete bibliography is included at the end of this overview. In order to obtain an impression of the extent and richness of his work, as well as a framework for the subsequent overview, we have categorized all his published articles based on a number of keywords in Table 1, at the price of an unavoidable lack of subtlety resulting from such a crude division.

\footnotetext{
1 Up to June 2012.

H. Peters · P. Sudhölter $(\varangle)$

Department of Quantitative Economics, Maastricht University, P.O. Box 616,

6200 MD Maastricht, The Netherlands

e-mail:psu@sam.sdu.dk

H. Peters

e-mail: h.peters@maastrichruniversity.nl

P. Sudhölter

Department of Business and Economics and COFERE, University of Southern Denmark, Campusvej 55, Odense M, Denmark
} 
Table 1 The order of topics in this table is roughly historical

\begin{tabular}{|c|c|c|c|}
\hline stable set (TU) & 1,4 & committees & $\begin{array}{l}49,54,55,58,108, \\
112,125\end{array}$ \\
\hline stable set (NTU) & 2,63 & monotonic SC & 56 \\
\hline bargaining set (TU) & $3,18,22,33,115,117,123$ & core of EF & $57,61,67$ \\
\hline bargaining set (NTU) & 6,7 & core (NTU) & $62,63,81$ \\
\hline quota games & $5,7,8,14,24,80$ & core (TU) & $\begin{array}{l}64,70,72,81,107, \\
113\end{array}$ \\
\hline (pre)kernel & $\begin{array}{l}8,12-16,20,33,50, \\
64,70,72,80,82,105\end{array}$ & $\begin{array}{l}\text { random SC } \\
\text { coalition-proof eq }\end{array}$ & $\begin{array}{l}65 \\
66,76,83,98 \\
101,110\end{array}$ \\
\hline events, automata & $9,21,84$ & biology, games & $75,79,84,92$ \\
\hline utility, pref, games & $10,17,26,59,60,74$ & least-core & 80 \\
\hline balanced collections & 11 & consistency Nash eq & $85,86,88,93$ \\
\hline eq points & 19,25 & consistency comp eq & 87,94 \\
\hline comp equilibrium & $27,39,46$ & auctions & 89 \\
\hline efficiency prices & $28-32,34-38,40,47,77$ & implementation & $90,91,114,119,126$ \\
\hline efficient rv & $42-44$ & $\mathrm{EF}$ and rights & 96 \\
\hline dyn systems, games & 45,69 & min compr (NTU) & 99 \\
\hline consistent voting & 48,122 & can ext form of gf & 100,103 \\
\hline representation by gf & $\begin{array}{l}49,68,110,111,116 \\
120,125\end{array}$ & $\begin{array}{l}\text { correlated eq } \\
\text { evolutionary analysis }\end{array}$ & $\begin{array}{l}104 \\
102,109\end{array}$ \\
\hline nucleolus & $50,72,80,97$ & convex games & 33,118 \\
\hline manipulability voting & 51,71 & Condorcet jury th & 127 \\
\hline
\end{tabular}

can canonical, comp competitive, compr compromise, dyn dynamic, $E F$ effectivity function, eq equilibrium, ext extensive, $g f$ game form, min minimal, $N T U$ nontransferable utility, pref preferences, $r v$ random variable, $S C$ social choice, $t h$ theorem, $T U$ transferable utility

In our overview of the work of Bezalel Peleg we distinguish three periods: the sixties, with a strong emphasis on cooperative game theory; the seventies, with an emphasis on economic models and the first works in social choice theory; and the eighties and onward, with seminal works in social choice, cooperative and noncooperative game theory.

\section{Early work: the sixties}

The first work of Bezalel Peleg concentrates on the stable set, the bargaining set, and the kernel for cooperative games. The stable set is the von Neumann and Morgenstern $^{2}$ stable set, at that time still plainly called the solution. The title of the first paper $[1,1959]$ of Bezalel Peleg is On the set of solvable n-person games: this means the set of (superadditive) $n$-person games with transferable utility (TU) that possess a

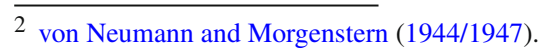


solution. At that time (1959) the general existence of such a solution was still an open problem. ${ }^{3}$ Bezalel Peleg shows that the subclass of all partial quota games has a solution and, moreover, that this subclass has the same dimension as the class of all games, and in particular that for a game picked at random the probability is positive that such a game is solvable. This paper draws on earlier work of Shapley (1953a) and Gillies (1953).

In [2, 1960] (with R. Aumann) the stable set is extended to cooperative games without sidepayments. This paper also explicitly formulates the important notions of $\alpha$-effectiveness (expressing what a coalition can attain by itself) and $\beta$-effectiveness (expressing what a coalition cannot be kept from), leading to $\alpha$ and $\beta$ versions of solutions, in particular of the core. The main result of this paper is that three-person zero-sum nontransferable utility (NTU) games are solvable. Paper [4, 1963] contains extensions and the proofs.

The early work of Bezalel Peleg also includes a first paper [3, 1963] (see also $[18,1967])$ with an existence result on the bargaining set $M_{1}^{(i)}$, proving a conjecture of Davis and Maschler (1963). Other work in this period concerns quota games [5, $1963 ; 7,1964 ; 8,1965]$, bargaining sets for games without sidepayments [6, 1963] and for quota games [7, 1964], and the kernel [8, 12, 13, 1965; 14, 15, 16, 1966; 20, 1967], which is a subset of the bargaining set $M_{1}^{(i)}$ for games with transferable utility. In $[15,1966]$ (with M. Maschler) an algebraic proof is provided of the existence of the kernel and, thus, of the bargaining set $M_{1}^{(i)}$ - earlier existence results were based on a fixed point argument. This method of proof-inspired by the computation of the kernel for quota games in $[12,1965]$ - uses the notion of separating collections of coalitions, studied further in [22, 1968] and also establishes that the intersection of the kernel and the core is nonempty if the core is nonempty.

The concept of balanced collections of coalitions is crucial for studying the core of games with and without transferable utility (sidepayments). ${ }^{4}$ In $[11,1965]$ Bezalel Peleg provides an inductive method to construct minimal balanced collections, that is, given the minimal balanced collections for a set of $n$ elements the method provides those for a set of $n+1$ elements.

Bezalel Peleg's early work also includes joint work with A. Paz in the area of information science $[9,1965 ; 21,1968]$ and work in the area of utility theory related to game theory $[10,1965]$. In $[17,1966]$ he outlines an approach to cooperative and noncooperative game theory without utility functions, based on preference relations only. He provides an existence result for equilibrium points (see also [19, 1967]) and proposes a dominance relation for cooperative games on which the core, the stable set, and bargaining sets can be based. In [25, 1969] an equilibrium existence result is proved for games with infinitely many players but finite pure strategy sets; the sufficient condition for existence used here is, roughly, that the set of payoff functions that only depend on finitely many players is dense in the set of all payoff functions. Finally, we mention [23, 1968] on centralized games and [24, 1968] on constant-sum majority games. A centralized game consists of a finite number of TU-games together

\footnotetext{
3 Solved later by Lucas (1969).

4 Bondareva (1962), Shapley (1967).
} 
with a collection of parties to which the players in the separate TU-games belong; in [23] the Shapley value ${ }^{5}$ of such a game is studied.

\section{Work in the seventies}

Bezalel Peleg's work in the seventies extends his work in game theory from the sixties but also broadens to general equilibrium theory.

His publications in this period with emphasis on game theory are [33, 1972] and [45, 1976]. In [33] (with M. Maschler and L. Shapley) it is shown that for convex games the bargaining set $M_{1}^{(i)}$ and the kernel (for the grand coalition) coincide with the core and the nucleolus, respectively. In [45] (with M. Maschler) a relation is established between stable sets of certain dynamic systems and generalized nucleoli.

In [26, 1970] Bezalel Peleg provides sufficient conditions for the existence of a utility function representing an irreflexive, transitive partial ordering on a topological space. The main condition is the existence of a countable subset 'separating' the ordering. 6

Most of the remaining work in this period is on general equilibrium models. Paper [27, 1970] (joint with M. Yaari) proves existence of competitive equilibrium in an exchange economy with countably many commodities. It is first proved that the core is nonempty and next the replication argument of Debreu and Scarf (1963) is used to establish existence of a competitive equilibrium. A reoccurring concept is that of efficiency prices in an economy: broadly, prices at which consumption bundles and/or production plans are Pareto optimal. In [30, 1970], again joint with M. Yaari, efficiency prices are studied in infinite dimensional space. The motivation provided for the work in both [27] and [30] is growth theory or, more generally, infinite horizon models. The concept of efficiency prices is further studied in a series of papers on efficiency prices for optimal consumption plans [28, 29, 1970; 31, 1971; 34, 1972; 36, 1973]. Competitive prices for optimal consumption plans are considered in [39, 1974] and $[46,1977]$, and optimal consumption plans in multisector economies in [32, 1972; 38, $1973 ; 40,1974]$, and later in [77, 1992].

Paper [37, 1973] (with M. Yaari) considers optimal consumption plans of an agent with preferences changing over time. ${ }^{7}$ This is viewed as a noncooperative game in which changed preferences are modelled by considering different players. An equilibrium consumption plan is a Nash equilibrium in this game. As a byproduct the paper provides a Nash equilibrium existence result for countably many players.

In $[42,1975]$ (with D. Levhari and J. Paroush) the familiar characterization of first order stochastic dominance in terms of expected utility is extended to multivariate distributions. In [43, 1975] (with M. Yaari) stochastic dominance among discrete random variables for risk averse decision makers is characterized in terms of efficiency prices. This work is extended to more general (nondiscrete) random variables in [44, 1975].

\footnotetext{
5 Shapley (1953b).

6 cf. Debreu (1954).

7 Following earlier work of Strotz (1956) and Pollak (1968).
} 
The main result of $[35,1972]$ is that set of efficient (Pareto optimal) points of a compact and convex subset of Euclidean space is contractible. The proof uses the Arrow-Barankin-Blackwell Theorem, ${ }^{8}$ which says that the set of regular efficient points (efficient points at which there is a supporting hyperplane with strictly positive normal) is dense in the set of all efficient points. This theorem is generalized to infinite dimensional spaces by Bezalel Peleg [28, 29, 1970], among others. In [47, 1978] the topological structure of the efficient point set under uncertainty as in [43] and [44] mentioned above is investigated.

Note [41, 1974] (with R. Aumann) provides an early example of endowment manipulation in a two person, two goods exchange economy.

\section{Work in the eighties and onwards}

We discuss the work of Bezalel Peleg since the end of the seventies under a number of headings.

\subsection{Strategic social choice}

A large part of the work of Bezalel Peleg starting at the end of the seventies and still continuing now is on social choice or, more precisely, in the overlapping area between social choice and game theory.

A first publication is $[48,1978]$ on so-called consistent voting systems. The Gibbard-Satterthwaite Theorem ${ }^{9}$ says that (in the classical social choice model with finitely many voters and alternatives) every nondictatorial social choice function with range at least three is manipulable. An 'exactly and strongly consistent' social choice function, as suggested in [48], is a social choice function with the property that for every preference profile there is a strong Nash equilibrium in the associated direct revelation game leading to the sincere outcome. This concept has been further explored in subsequent work of several authors, including Bezalel Peleg and coauthors: see Chaps. 4 and 5 of [B1, 1984], Part II of [B3, 2010], and [122, 2006] (with H. Peters), extending the concept and results to models with a continuum of voters. In [126, 2010] (with A. Procaccia) another way to escape the negative consequences of the Gibbard-Satterthwaite Theorem is proposed, namely through the concept of mediated equilibrium or equilibrium with threats (see also Chap. 8 in [B3]).

Another central concept in the work of Bezalel Peleg is that of an effectivity function. An effectivity function is a mapping from coalitions of players to collections of sets of alternatives, describing what coalitions can obtain by cooperating. Effectivity functions can arise in many ways: from social choice functions or correspondences, from simple (cooperative) games, from strategic (noncooperative) games and in particular from game forms. An effectivity function can also be considered as a primitive concept. In [57, 1982] (joint with H. Moulin) the question is answered under which

\footnotetext{
8 Arrow et al. (1953).

9 Gibbard (1973), Satterthwaite (1975).
} 
conditions an effectivity function can be represented by a game form such that for each profile of preferences the resulting game has a strong Nash equilibrium-see also Chap. 6 in [B1, 1984]. The connection between simple games (committees) and social choice functions and correspondences is explored in several publications, notably $[49,1978 ; 52,1979 ; 54,1980 ; 55,1981]$ and $[58,1983]$. See also $[56,1981]$ and [61, 1984].

In $[96,1998]$ effectivity functions are used to model constitutions, thus establishing a connection with the theory of rights. ${ }^{10}$ A game form is developed that represents a given effectivity function. Such a game form is Nash consistent if it has a Nash equilibrium for every profile of preferences (further developed in [111, 2002] with H. Peters and T. Storcken); it is acceptable ${ }^{11}$ if Nash equilibria are Pareto optimal (see also [116, 2004]); it is strong or strongly Nash consistent if it has a strong Nash equilibrium for every preference profile (see [57] discussed above). Constitutional implementation refers to implementation (of social choice functions or correspondences) while preserving power, that is, not changing the effectivity function: see [114, 2002] (with E. Winter) and [119, 2005] (with H. Peters and T. Storcken). Further work in this area includes representation in coalition-proof Nash equilibrium (see also below) in [110, 2002], continuity of representations in [120, 2006], and binary effectivity rules in $[121,2006]$ (all with H. Keiding), and Nash consistent representation through lottery models in [125, 2009] (with H. Peters). Related papers are [108, 2001] (with H. Keiding) and [112, 2002]. In Part I of [B3] much of this literature is reviewed and partially extended. Publication [68, 1988] (with C. d'Aspremont) deals with representations of committees (simple games) in the context of incomplete information.

Works on voting and specifically on manipulability in social choice include [51, 1979; 71, 1990; 73, 1991], and [78, 1992]. In [51] the notion of asymptotic nonmanipulability of voting systems is defined, and studied in particular for positionalist voting systems, i.e., voting systems which can be based on scoring methods. In [71] (with S. Barberà) the Gibbard-Satterthwaite Theorem (footnote 13 ) is extended to a more general domain of continuous preferences; the proof is based on the useful notion of an option set. Probabilistic social choice rules under an Arrovian condition of independence of irrelevant alternatives, resulting in random dictatorship, are the subject of $[65,1986]$ (with P. Pattanaik). An extension of the Condorcet Jury Theorem to dependent juries is offered in [128, 2012] (joint with S. Zamir).

Papers [90, 1996] and [91, 1996] are concerned with double implementation of Walras and of Lindahl equilibrium. The adjective 'double' refers to the fact that (e.g.) not only the Walrasian equilibria of the economy coincide with the Nash equilibria of the game form or mechanism but also these Nash equilibria are strong, that is, resistent against coalitional deviations.

\footnotetext{
10 Following Gärdenfors (1981).

11 See also Hurwicz and Schmeidler (1978) and Dutta (1984).
} 


\subsection{Noncooperative game theory}

In [66, 1987] (with B. Bernheim and M. Winston) the new equilibrium concept of coalition-proof Nash equilibrium was introduced. This concept is stronger than Nash equilibrium since it also takes coalitional deviations into account, but weaker than strong Nash equilibrium, since it only takes specific credible deviations into account. An additional advantage is that its existence is less often a problem than is the case for strong Nash equilibrium. Further works on coalition-proof Nash equilibrium and its applications are [76, 1992; 83, 1995; 98, 1998], and [110, 2002]. In [101, 1999] (with P. Sudhölter) it is shown that in a model with single-peaked preferences generalized median voter schemes ${ }^{12}$ induce game forms in which truthful voting is a coalitionproof Nash equilibrium.

Starting with [85, 1996] (with S. Tijs) there is a stream of results about axiomatic characterizations of Nash equilibria in games and of the Walrasian correspondence in economies based on a consistency principle. This consistency principle states, basically, that if we fix the strategies of some players or the allocations of some agents then the strategies of the remaining players or the allocations of the remaining agents in the thus reduced game or economy do not change. For games, this avenue of research is further explored in [86, 1996] (with J. Potters and S. Tijs), [88, 1996] (with R. Heumen, S. Tijs and P. Borm), and [93, 1997] (with P. Sudhölter). For economies the relevant papers are $[87,1996]$ (with A. van den Nouweland and S. Tijs) and [94, 1997] (with A. Majumdar).

\subsection{Cooperative game theory}

Cooperative game theory keeps on playing an important role in the work of Bezalel Peleg since the eighties. In [50, 1979] (with M. Maschler and L. Shapley) geometric properties of the kernel, the nucleolus and related solution concepts are investigated. Axiomatic treatments of the core and related concepts, in which the Davis-Maschler reduced game property ${ }^{13}$ is central, are the subject of $[62,1985 ; 64,1986 ; 70,1993$; 72, 1990; 81, 1992], and [113, 2002] (with P. Sudhölter). In [63, 1986] it is shown that the core of an ordinal convex game without sidepayments is a von NeumannMorgenstern stable set. Cores of compound simple games are studied in [67, 1987]. The least-core, nucleolus and kernel of homogeneous weighted majority games are the subject of [80, 1992] (with J. Rosenmüller). See also [82, 1994] (with P. Sudhölter and J. Rosenmüller) on the kernel of homogeneous games. On the nucleolus and the prekernel see $[97,1998]$ and $[105,2000]$ (both with P. Sudhölter). On bargaining sets see [115, 2002; 117, 2005] (with P. Sudhölter), and [123, 2007] (with R. Holzman and P. Sudhölter).

In [74, 1991] (with E. Einy) linear measures of inequality for cooperative games are considered, and in [107, 2001] (with J. L. Hougaard and L. Thorlund-Petersen) Lorenz-maximal imputations in the core of a cooperative game. The Dutta-Ray

\footnotetext{
12 Moulin (1980).

13 Davis and Maschler (1965).
} 
solution ${ }^{14}$ for convex games is generalized in [118, 2005] (with J.L. Hougaard and L. P. Østerdal).

Further works on cooperative games include [69, 1988] (with M. Maschler and G. Owen) on paths leading to the Nash set, i.e., the set of Nash bargaining outcomes in a nonconvex cooperative bargaining game; [99, 1998] (with P. Borm, G.-J. Otten and S. Tijs) on the minimal compromise value for games without sidepayments; [124, 2008] (with B. O'Neill) on lexicographic composition of simple games; and [127, 2012] (with P. Sudhölter and J. Zarzuelo) on two-person NTU-games.

Last but not least, the book 'Introduction to the Theory of Cooperative Games' [B2, 2003, 2007] (with P. Sudhölter) has become a classical work on cooperative game theory.

\subsection{Other topics}

The extension of an ordering over a set of alternatives to the power set, i.e., to subsets of alternatives, has received attention in two works, namely [59, 1984] (with Y. Kannai) and [60, 1984] (with P. Pattanaik).

Contributions to biology from a game-theoretic point of view and in particular to theories about the behavior of bees are [75, 1992] (with A. Shmida), [79, 1992] (with A. Shmida and S. Ellner), [84, 1995] (with F. Thuijsman, M. Amitai, and A. Shmida), and $[92,1997]$.

In [102, 2000] (with W. Güth and H. Kliemt) and [109, 2001] (with W. Güth) evolutionary analysis is applied to human behavior in games of trust and in games in which payoffs depend not only on chosen strategies but also on genetically determined stimuli.

Remaining works on diverse topics include the following. In [89, 1996] (with W. Güth) ring formation in auctions is considered. The canonical extensive form of a game form is studied in $[100,1999]$ and $[103,2000]$ (with J. Rosenmüller and P. Sudhölter). In [95, 1997] a critical consideration of the 'Nash program' (which seeks to 'back up' cooperative or axiomatic solution concepts by noncooperative games, not to be confused with various types of implementation) is presented. Correlated equilibria in games with many players are studied in [104, 2000] (with H. Keiding).

\section{Epilogue}

The richness, breadth and depth of Bezalel Peleg's work should be apparent from the above overview and from the list of publications below. Additional words of support seem redundant. We also refrain from identifying 'research highlights': any reader may judge for himself. As co-authors and friends of Bezalel, we would like to express that it has been and is an honor and pleasure to work with him, not just because of his intellectual qualities but also because of his openness and friendliness. Thank you very much!

14 Dutta and Ray (1989). 


\section{List of publications}

Books

B1. Game Theoretic Analysis of Voting in Committees. Cambridge University Press, Cambridge, UK, 1984.

B2. Introduction to the Theory of Cooperative Games. Kluwer Academic Publishers, Dordrecht, 2003. Second edition by Springer-Verlag, 2007 (joint with P. Sudhölter).

B3. Strategic Social Choice: Stable Representations of Constitutions. SpringerVerlag, Heidelberg, 2010 (joint with H. Peters).

Articles

1. "On the set of solvable n-person games", Bulletin of the American Mathematical Society, 65 (1959), 380-383.

2. "Von Neumann-Morgenstern solutions to cooperative games without side payments", Bulletin of the American Mathematical Society, 66 (1960), 173-179 (with R. J. Aumann).

3. "Existence theorem for the bargaining set $M_{1}^{(i)}$ ", Bulletin of the American Mathematical Society, 69 (1963), 109-110.

4. "Solutions to cooperative games without side payments", Transactions of the American Mathematical Society, 106 (1963), 280-292.

5. "Quota games with continuum of players", Israel Journal of Mathematics, 1 (1963), 48-53.

6. "Bargaining sets of cooperative games without side payments", Israel Journal of Mathematics, 1 (1963), 197-200.

7. "On the bargaining set $M_{0}$ of $m$-quota games", Advances in Game Theory, Annals of Mathematics Studies 52, Princeton University Press, 1964, 501-512.

8. "The kernel of $m$-quota games", Canadian Journal of Mathematics, 17 (1965), 239-244.

9. "Ultimate-definite and symmetric-definite events and automata", Journal of the Association for Computing Machinery, 12 (1965), 399-410 (with A. Paz).

10. "Utility functions of money for clear games", Naval Research Logistics Quarterly, 12 (1965), 57-63.

11. "An inductive method for constructing minimal balanced collections of finite sets”, Naval Research Logistics Quarterly, 12 (1965), 155-162.

12. "A method for computing the kernel of n-person games", Mathematics of Computation, 19 (1965), 531-551 (with R. J. Aumann and P. Rabinowitz).

13. "The kernel of the composition of characteristic function games", Israel Journal of Mathematics, 3 (1965), 127-138.

14. "On the kernel of constant-sum simple games with homogeneous weights", Illinois Journal of Mathematics, 10 (1966), 39-48.

15. "A characterization, existence proof and dimension bounds for the kernel of a game", Pacific Journal of Mathematics, 18 (1966), 289-328 (with M. Maschler). 
16. "The kernel of the general sum four-person game", Canadian Journal of Mathematics, 18 (1966), 673-677.

17. "The independence of game theory of utility theory", Bulletin of the American Mathematical Society, 72 (1966), 995-999.

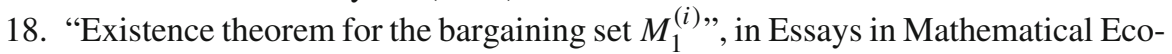
nomics in Honor of O. Morgenstern, ed. M. Shubik, Princeton University Press (1967), 53-56 (a detailed version of [3.]).

19. "Equilibrium points for open acyclic relations", Canadian Journal of Mathematics, 19 (1967), 366-369.

20. "The structure of the kernel of a cooperative game", SIAM Journal on Applied Mathematics, 15 (1967), 569-604 (with M. Maschler).

21. "On concatenative decompositions of regular events", IEEETC, C-17 (1968), 229-237 (with A. Paz).

22. "On minimal separating collections", Proceedings of the American Mathematical Society, 19 (1968), 26-30.

23. "Centralized games", SIAM Journal on Applied Mathematics, 16 (1968), 102-104.

24. "On weights of constant-sum majority games", SIAM Journal on Applied Mathematics, 16 (1968), 527-532.

25. "Equilibrium points for games with infinitely many players", Journal of the London Mathematical Society, 44 (1969), 292-294.

26. "Utility functions for partially ordered topological spaces", Econometrica, 38 (1970), 93-96.

27. "Markets with countable many commodities", International Economic Review, 11 (1970), 369-377 (with M. E. Yaari).

28. "Efficiency prices for optimal consumption plans", Journal of Mathematical Analysis and Applications, 29 (1970), 83-90.

29. "Efficiency prices for optimal consumption plans III", Journal of Mathematical Analysis and Applications, 32 (1970), 630-638.

30. "Efficiency prices in an infinite-dimensional space", Journal of Economic Theory, 2 (1970), 41-85 (with M. E. Yaari).

31. "Efficiency prices for optimal consumption plans II", Israel Journal of Mathematics, 9 (1971), 222-234.

32. "On optimal consumption plans in a multi-sector economy", The Review of Economic Studies, 39 (1972), 159-169 (with H. E. Ryder, Jr.).

33. "The kernel and bargaining set for convex games", International Journal of Game Theory, 1 (1972), 73-93 (with M. Maschler and L. S. Shapley).

34. "Efficiency prices for optimal consumption plan IV", Siam Journal on Control, 10 (1972), 414-433.

35. "Topological properties of the efficient point set", Proceedings of the American Mathematical Society, 35 (1972), 531-536.

36. "Price properties of optimal consumption programs", in Models of Economic Growth, eds. J. A. Mirrlees and N. H. Stern, Macmillan, London (1973), 306-317 (with M. E. Yaari). 
37. "On the existence of a consistent course of action when tastes are changing", The Review of Economic Studies, 40 (1973), 391-401 (with M. E. Yaari).

38. "A weakly maximal golden rule programme for a multi-sector economy", International Economic Review, 14 (1973), 574-579.

39. "On competitive prices for optimal consumption plans", SIAM Journal on Applied Mathematics, 26 (1974), 239-253.

40. "The modified golden-rule of a multi-sector economy", Journal of Mathematical Economics, 1 (1974), 193-198 (with H. E. Ryder, Jr.).

41. "A note on Gale's example", Journal of Mathematical Economics, 1 (1974), 209-211 (with R. J. Aumann).

42. "Efficiency analysis for multi-variate distributions", The Review of Economic Studies, 42 (1975), 87-91 (with D. Levhari and J. Paroush).

43. "A price characterization of efficient random variables", Econometrica, 43 (1975), 283-292 (with M. E. Yaari).

44. "Efficient random variables", Journal of Mathematical Economics, 2 (1975), 243-252.

45. "Stable sets and stable points of set-valued dynamic systems with applications to game theory", SIAM Journal on Control and Optimization, 14 (1976), 985-995 (with M. Maschler).

46. "On competitive prices for optimal consumption plans II", SIAM Journal on Applied Mathematics, 32 (1977), 627-630 (with I. Zilcha).

47. "Topological properties of the efficient point set II", Journal of Mathematical Analysis and Applications, 63 (1978), 377-384.

48. "Consistent voting systems", Econometrica, 46 (1978), 153-161.

49. "Representations of simple games by social choice functions", International Journal of Game Theory, 7 (1978), 81-94.

50. "Geometric properties of the kernel, nucleolus, and related solution concepts", Mathematics of Operations Research, 4 (1979), 303-338 (with M. Maschler and L. S. Shapley).

51. "A note on manipulability of large voting schemes", Theory and Decision, 11 (1979), 401-412.

52. "Game theoretic analysis of voting schemes", in Game Theory and Related Topics, eds. O. Moeschlin and D. Pallaschke, North-Holland, Amsterdam (1979), 83-89.

53. "An approach to the problem of efficient distribution of the labor force", in Applied Game Theory, eds. S. J. Brams, A. Schotter, and G. Schwödiauer, Physica-Verlag, Vienna (1979), 214-235 (with Y. Kannai).

54. "A theory of coalition formation in committees", Journal of Mathematical Economics, 7 (1980), 115-134.

55. "Coalition formation in simple games with dominant players", International Journal of Game Theory, 10 (1981), 11-33.

56. "Monotonicity properties of social choice correspondences", in Game Theory and Mathematical Economics, eds. O. Moeschlin and D. Pallaschke, NorthHolland, Amsterdam (1981), 97-101.

57. "Cores of effectivity functions and implementation theory", Journal of Mathematical Economics, 10 (1982), 115-145 (with H. Moulin). 
58. "On simple games and social choice correspondences", in Social Choice and Welfare, eds. P. K. Pattanaik and M. Salles, North-Holland, Amsterdam (1983), 251-268.

59. "A note on the extension of an order on a set to the power set", Journal of Economic Theory, 32 (1984), 172-175 (with Y. Kannai).

60. "An axiomatic characterization of the lexicographic maximum extension of an ordering over a set to the power set", Social Choice and Welfare, 1 (1984), 113-122 (with P. K. Pattanaik).

61. "Core stability and duality of effectivity functions", in Selected Topics in Operations Research and Mathematical Economics, eds. G. Hammer and D. Pallaschke, Springer-Verlag, Berlin (1984), 272-287.

62. "An axiomatization of the core of cooperative games without side payments", Journal of Mathematical Economics, 14 (1985), 203-214.

63. "A proof that the core of an ordinal convex game is a von Neumann-Morgenstern solution", Mathematical Social Sciences, 11 (1986), 83-87.

64. "On the reduced game property and its converse", International Journal of Game Theory, 15 (1986), 187-200. A correction: International Journal of Game Theory, 16 (1987), 290.

65. "Distribution of power under stochastic social choice rules", Econometrica, 54 (1986), 909-921 (with P. K. Pattanaik).

66. "Coalition-proof Nash equilibria-I. Concepts", Journal of Economic Theory, 42 (1987), 1-12 (with B. D. Bernheim and M. D. Whinston).

67. "Cores and capacities of compound simple games", Social Choice and Welfare (1987) 307-316.

68. "Ordinal Bayesian incentive compatible representations of committees", Social Choice and Welfare, 5 (1988), 261-279 (with C. d'Aspremont).

69. "Paths leading to the Nash set", in the Shapley Value: Essays in Honor of Lloyd S. Shapley, ed. A. E. Roth, Cambridge University Press, Cambridge (1988), 321-330 (with M. Maschler and G. Owen).

70. "An axiomatization of the core of market games", Mathematics of Operations Research, 14 (1989), 448-456. A correction: Mathematics of Operations Research, 18 (1993), 765.

71. "Strategy-proof voting schemes with continuous preferences", Social Choice and Welfare, 7 (1990), 31-38 (with S. Barberà).

72. "Axiomatizations of the core, the nucleolus, and the prekernel", in Game Theory and Applications, eds. T. Ichiishi, A. Neyman, and Y. Tauman, Academic Press, New York (1990), 176-182.

73. "A solution to the problem of mass elections", in Issues in Contemporary Economics, Volume 1: Markets and Welfare, ed. K. J. Arrow, Macmillan, London (1991), 287-294.

74. "Linear measures of inequality for cooperative games", Journal of Economic Theory, 53 (1991), 328-344 (with E. Einy).

75. "Short-run stable matchings between bees and flowers", Games and Economic Behavior, 4 (1992), 232-251 (with A. Shmida). 
76. “On perfectly coalition-proof Nash equilibria", in Equilibrium and Dynamics: Essays in Honor of David Gale, ed. M. Majumdar, Macmillan, London (1992), 259-268.

77. "A note on optimal development in a multi-sector nonconvex economy", in Equilibrium and Dynamics: Essays in Honor of David Gale, ed. M. Majumdar, Macmillan, London (1992), 241-246 (with M. Majumdar).

78. "Voting by count and account", in Rational Interaction: Essays in Honor of John C. Harsanyi, ed. R. Selten, Springer-Verlag, Berlin (1992), 45-51.

79. "Foraging graphs: constraint rules on matching between bees and flowers in a two sided pollination market", Journal of Theoretical Biology, 157 (1992), 191-201 (with A. Shmida and S. Ellner).

80. "The least-core, nucleolus, and kernel of homogeneous weighted majority games", Games and Economic Behaviour, 4 (1992), 588-605 (with J. Rosenmüller).

81. "Axiomatizations of the core", in Handbook of Game Theory, Vol. 1, eds. R. J. Aumann and S. Hart, North-Holland, Amsterdam (1992), 398-412.

82. "The kernel of homogeneous games with steps", in Essays in Game Theory in Honor of M. Maschler, ed. N. Megiddo, Springer-Verlag, Berlin, (1994), 163-192 (with J. Rosenmüller and P. Sudhölter).

83. "Coalition-proof communication equilibria", in Social Choice, Welfare, and Ethics, eds. W. A. Barnett, H. Moulin, M. Salles, and N. J. Schofield, Cambridge University Press (1995), 289-300 (with E. Einy).

84. "Automata matching and foraging behaviour of bees", Journal of Theoretical Biology, 175 (1995), 305-316 (with F. Thijsman, M. Amitai, and A. Shmida).

85. "The consistency principle for games in strategic form", International Journal of Game Theory, 25 (1996), 13-34 (with S. Tijs).

86. "Minimality of consistent solutions for strategic games", Economic Theory, 7 (1996), 81-93 (with J. Potters and S. Tijs).

87. "Axiomatic characterization of the Walras correspondence for generalized economies", Journal of Mathematical Economics, 25 (1996), 335-372 (with A. van den Nouweland and S. Tijs).

88. "Axiomatic characterization of solutions for extended Bayesian games", Theory and Decision, 40 (1996), 103-129 (with R. Heumen, S. Tijs and P. Borm).

89. “On ring formation in auctions", Mathematical Social Sciences, 32 (1996), 1-37 (with W. Güth).

90. "A continuous double implementation of the constrained Walras equilibrium", Economic Design, 2 (1996), 89-97.

91. "Double implementation of the Lindahl equilibrium by a continuous mechanism", Economic Design, 2 (1996), 311-324.

92. "Strict and symmetric correlated equilibria are the distributions of the ESS's of biological conflicts with asymmetric roles", in Understanding Strategic Interaction, Essay in Honor of Reinhard Selten, eds. W. Albers, W. Güth, P. Hammerstein, B. Moldovanu, and E. van Damme, Springer-Verlag (1997), 149-170 (with A. Shmida).

93. "An axiomatization of Nash equilibria in economic situations", Games and Economic Behavior, 18 (1997), 277-285 (with P. Sudhölter). 
94. "An axiomatization of the Walras correspondence in infinite dimensional spaces", International Economic Review, 38 (1997), 853-864 (with M. Majumdar).

95. "A difficulty with Nash's program: a proof of a special case", Economics Letters, 55 (1997), 305-308.

96. "Effectivity functions, game forms, games, and rights", Social Choice and Welfare, 15 (1998), 67-80.

97. "Nucleoli as maximizers of collective satisfaction functions", Social Choice and Welfare 15 (1998), 383-411 (with P. Sudhölter). A correction: Social Choice and Welfare, 17 (2000), 379-380.

98. "Almost all equilibria in dominant strategies are coalition-proof", Economics Letters, 60 (1998), 157-162.

99. "The MC-value for monotonic NTU-games", International Journal of Game Theory, 27 (1998), 37-47 (with P. Borm, G.-J. Otten, and S. Tijs).

100. "The canonical extensive form of a game form: symmetries", in Current Trends in Economics: Theory and Applications, eds. A. Alkan, C. D. Aliprantis, and N. C. Yannelis, Spinger-Verlag (1999), 367-387 (with J. Rosenmüller and P. Sudhölter).

101. "Single-peakedness and coalition-proofness", Review of Economic Design, 4 (1999), 381-387 (with P. Sudhölter).

102. "Co-evolution of preferences and information in simple games of trust", German Economic Review, 1 (2000), 83-110 (with W. Güth and H. Kliemt).

103. "The canonical extensive form of a game form: part II-representation", Journal of Mathematical Economics, 33 (2000), 299-338 (with J. Rosenmüller and P. Sudhölter).

104. "Correlated equilibria of games with many players", International Journal of Game Theory, 29 (2000), 375-389 (with H. Keiding).

105. "The positive prekernel of a cooperative game", International Game Theory Review, 2 (2000), 287-305 (with P. Sudhölter).

106. "Reconciling power and equality in international organizations: a voting method from Rabbi Krochmal of Kremsier", Jewish Political Studies Review, 12 (2000), 67-81 (with B. O’Neill).

107. "On the set of Lorenz-maximal imputations in the core of a balanced game", International Journal of Game Theory, 30 (2001), 147-165 (with J. L. Hougaard and L. Thorlund-Petersen).

108. "Stable voting procedures for committees in economic environments", Journal of Mathematical Economics, 36 (2001), 117-140 (with H. Keiding).

109. "When will payoff maximization survive? An indirect evolutionary analysis", Journal of Evolutionary Economics, 11 (2001), 479-499 (with W. Güth).

110. "Representation of effectivity functions in coalition proof Nash equilibrium: a complete characterization", Social Choice and Welfare, 19 (2002), 241-263 (with H. Keiding).

111. "Nash consistent representation of constitutions: a reaction to the Gibbard paradox", Mathematical Social Sciences, 43 (2002), 267-287 (with H. Peters and T. Storcken). 
112. "Game-theoretic analysis of voting in committees", in Handbook of Social Choice and Welfare, Vol. 1, eds. K. J. Arrow, A. K. Sen, and K. Suzumura, North-Holland, Amsterdam (2002), 395-423.

113. "A note on axiomatization of the core of market games", Mathematics of Operations Research, 27 (2002), 441-444 (with P. Sudhölter).

114. "Constitutional implementation", Review of Economic Design, 7 (2002), 187-204 (with E. Winter).

115. "The dummy paradox of the bargaining set", in Game Theory and Applications, vol. 8, eds. L. A. Petrosjan and V. V. Mazalov, Nova Science Publishers, New York (2002), 119-124 (with P. Sudhölter).

116. "Representation of effectivity functions by acceptable game forms: a complete characterization", Mathematical Social Sciences, 47 (2004), 275-287.

117. "On the non-emptiness of the Mas-Colell bargaining set", Journal of Mathematical Economics, 41 (2005), 1060-1068 (with P. Sudhölter).

118. "The Dutta-Ray solution on the class of convex games: a generalization and monotonicity properties", International Game Theory Review, 7 (2005), 431442 (with J. L. Hougaard and L. P. Østerdal).

119. "Constitutional implementation of social choice correspondences", International Journal of Game Theory, 33 (2005), 381-396 (with H. Peters and T. Storcken).

120. "On the continuity of representations of effectivity functions", Journal of Mathematical Economics, 42 (2006), 827-842 (with H. Keiding).

121. "Binary effectivity rules", Review of Economic Design, 10 (2006), 167-181 (with H. Keiding).

122. "Consistent voting systems with a continuum of voters", Social Choice and Welfare, 27 (2006), 477-492 (with H. Peters).

123. "Bargaining sets of majority voting games", Mathematics of Operations Research, 32 (2007), 857-872 (with R. Holzman and P. Sudhölter).

124. "Lexicographic composition of simple games", Games and Economic Behavior, 62 (2008), 628-642 (with B. O’Neill).

125. "Nash consistent representation of effectivity functions through lottery models", Games and Economic Behavior, 65 (2009), 503-515 (with H. Peters).

126. "Implementation by mediated equilibrium", International Journal of Game Theory, 39 (2010), 191-207 (with A. D. Procaccia).

127. "On the impact of independence of irrelevant alternatives: the case of two-person NTU games”, SERIEs, 3 (2012), 143-156 (with P. Sudhölter and J. M. Zarzuelo).

128. "Extending the Condorcet jury theorem to a general dependent jury", Social Choice and Welfare, 39 (2012), 91-125 (with S. Zamir).

\section{References}

Arrow KJ, Barankin EW, Blackwell D (1953) Admissible points of convex sets. In: Contributions to the theory of games 2. Annals of mathematics studies, vol 28. Princeton University Press, Princeton, pp 87-91

Bondareva ON (1962) Theory of the core in the $n$-person game. Vestn Leningr Univ 13:141-142 (in Russian)

Davis M, Maschler M (1963) Existence of stable payoff configurations of cooperative games. Bull Am Math Soc 69:106-108 
Davis M, Maschler M (1965) The kernel of a cooperative game. Nav Res Logist Q 12:223-259

Debreu G (1954) Representation of a preference ordering by a numerical function. In: Thrall RM, Coombs $\mathrm{CH}$, Davis RL (eds) Decision processes. Wiley, New York pp 159-165

Debreu G, Scarf H (1963) A limit theorem on the core of an economy. Int Econ Rev 4:235-246

Dutta B (1984) Effectivity functions and acceptable game forms. Econometrica 52:1151-1166

Dutta B, Ray D (1989) A concept of egalitarianism under participation constraints. Econometrica 57: 615-635

Gärdenfors P (1981) Rights, games, and social choice. Noûs 15:341-356

Gibbard A (1973) Manipulation of voting schemes: a general result. Econometrica 41:587-602

Gillies DB (1953) Discriminatory and bargaining solutions to a class of symmetric $n$-person games. In: Contributions to the theory of games II. Princeton University Press, Princeton, pp 325-342

Hurwicz L, Schmeidler D (1978) Construction of outcome functions guaranteeing existence and Pareto optimality of Nash equilibria. Econometrica 46:1447-1474

Lucas WF (1969) The proof that a game may not have a solution. Trans Am Math Soc 136:219-229

Moulin H (1980) On strategy-proofness and single-peakedness. Public Choice 35:437-455

Pollak RA (1968) Consistent planning. Rev Econ Stud 35:185-199

Satterthwaite M (1975) Strategy-proofness and Arrow's conditions: existence and correspondence theorems for voting procedures and social welfare functions. J Econ Theory 10:187-217

Shapley LS (1953a) Quota solutions of $n$-person games. In: Contributions to the theory of games II. Princeton University Press, Princeton, pp 343-360

Shapley LS (1953b) A value for $n$-person games. In: Contributions to the theory of games II. Princeton University Press, Princeton, pp 307-317

Shapley LS (1967) On balanced sets and cores. Nav Res Logist Q 14:453-460

Strotz RH (1956) Myopia and inconsistency in dynamic utility maximization. Rev Econ Stud 23:156-180

von Neumann J, Morgenstern O (1944/1947) Theory of games and economic behavior. Princeton University Press, Princeton 